\title{
Contexts in philosophy: pragmatic competence as filter
}

\section{Les contextes en philosophie : la compétence pragmatique comme filtre}

\author{
Carlo Penco ${ }^{1}$ \\ ${ }^{1}$ University of Genoa, penco@unige.it
}

RÉSUMÉ. Ce papier tente de connecter des préoccupations dans la philosophie du langage avec des vues traditionnelles en Intelligence Artificielle. Après une courte introduction sur la notion de contexte en Philosophie ( 1 1), je pars de l'inventeur de la logique mathématique, Gottlob Frege pour présenter trois débats dans la philosophie du langage où la solution est fortement indécise : (§2) le débat sur l'holisme, (§3) le débat sur les frontières entre sémantique et pragmatique, et (§4) le débat entre les vues explicites et implicites de descriptions incomplètes. Ces débats peuvent être considérés comme des études de cas sur ce qui est arrivé à la notion de contexte en Philosophie dans les deux premières décades du XXlième siècle ; ils nous poussent à chercher un cadre unifiée pour cadrer les soucis dont nous discutons : je propose de déplacer l'attention vers une représentation des capacités élémentaires qui sont requises pour naviguer à travers les contextes (§5). Je conclue en faisant quelques suggestions issues des Sciences de l'Informatique pour contribuer à une meilleure définition de la signification de «compétence pragmatique » dans le cadre d'une entreprise philosophique (§6).

ABSTRACT. This programmatic paper is an attempt to connect some worries in the philosophy of language with some traditional views in artificial intelligence. After a short introduction to the notion of context in philosophy ( $\$ 1$ ), starting from the inventor of mathematical logic, Gottlob Frege, I list three debates in the philosophy of language where the solution is strongly undecided: $§ 2$ treats the debate between holism and molecularism; §3 describes the debate on the boundaries between semantics and pragmatics; $\$ 4$ hints at a solution of the debate between explicit and implicit view of incomplete descriptions. These debates may be considered case studies on what is happening to the notion of context in philosophy in the first two decades of XXI century; they push us to look for a unifying framework in which to frame those worries: I propose to shift the attention towards a representation of the basic abilities required to navigate across contexts $(\S 5)$. In the conclusion, I use some suggestions from computer sciences as a contribution towards a better definition of what is meant by "pragmatic competence", strictly connected to the philosophical enterprise (§6).

MOTS-CLÉS. Indexicals, signification, sous-détermination, compétence pragmatique, frontières sémantiquespragmatiques.

KEYWORDS. Indexicals, meaning - underdetermination, pragmatic competence, semantic-pragmatics boundaries.

\section{Varieties of contexts in philosophy}

Philosophers developed a strong interest on the topic of context ${ }^{1}$ since Frege's work on the foundation of mathematical logic. Dummett [36] invented the term "context-principle" to tag the Fregean principle presented in his Grundlagen der Arithmetik:

(1) "Never to ask for the meaning of a word in isolation, but only in the context of a sentence" [46: p. xxii]

The idea of context is that of being connected or "staying together" ("zusammenhang"). Frege's proposal was an expression of his anti-psychologistic stance against the identification of meaning with "ideas", a view traditionally shared by empiricists and rationalists. John Locke, in the Essay on Human understanding, claims that the meaning of a word is the idea in the mind to which the word corresponds. ${ }^{2}$ Certainly, Locke had a very important, predecessor: according to Aristotle words are "signs of the movement of the mind": they don't signify objects, but ideas in the mind (Aristotle: De interpretatione). Frege thought that Locke's mistake was to look for the meaning of a word in isolation and proposed two arguments against the traditional view: (i) for many words there are no corresponding ideas, and the only way to understand or define the meaning of a word is to study how it works in the context of a sentence; (ii) different people may connect different ideas with the same

\footnotetext{
${ }^{1}$ In this section I develop what was presented in [100]

${ }^{2}$ Christopher Gauker gives a general criticism of Locke's expressivist view of meaning in [49].

(c) 2018 ISTE OpenScience - Published by ISTE Ltd. London, UK - openscience.fr
} 
words. Locke thought that the habit of using words would help go beyond misunderstandings. Frege required something more open to view: the study of the behaviour of words in the context of sentences. A first notorious application of these ideas is the individuation of the problem (and the first attempted solution) of indirect contexts (contexts like "John says/believes/knows that p"), where general principles of substitutivity and compositionality seem to fail. ${ }^{3}$

A second suggestion came from Frege's worries about aspects of natural language that go beyond the mere linguistic expression; working in mathematics we work on expressions (e.g. numerals) that always refer to the same objects (e.g. numbers). On the contrary, in everyday speech, expressions like "I", "today", "yesterday", "this", "that", "here", "there" require the knowledge of the surrounding circumstances in order to understand the object to which we refer:

(2) «The mere wording, as it can be written down, is not the complete expression of the thought; the knowledge of certain circumstances accompanying the utterance, which are used as means of expressing the thought, is needed for us to grasp the thought correctly. Pointing the finger, hand gestures, glances may belong here too. The same verbal expression of the word "I" will express different thoughts in the mouths of different men, of which some may be true, others false» [48: p. 64]

Expressions like "I" or "here" or "now" are "context-dependent", and in this quotation Frege actually refers to the context of utterance as distinguished by the linguistic context of a sentence.

A third suggestion came from a side remark on the difficulties of natural language where we have expressions that can be empty if they do not refer to any existing object. Frege suggested that when we use a definite description in natural language we presuppose the existence of the individual defined by the description. Here the truth conditions of a sentence do not depend on the objective context of utterance, but on a shared agreement on presuppositions triggered by features of natural language like the definite article used to build definite descriptions like "the inventor of bifocals", "the President of US", descriptions that Frege called "composed proper names". As Frege said:

(3) «When we make an assertion, we give it for presupposed that the simple or composed proper name has a reference» $[47]^{4}$

These three ideas have been the source of different concepts of context, often overlapping each other:

(1) linguistic context

(2) utterance context

(3) cognitive context.

This three-partition is not exhaustive, but may help to find a way in the web of definitions of context (Patrick Brézillon [18] refers to 250 different definitions of context found in the web). Linguistic context or co-text is mainly studied by linguists and concerns phenomena like discourse, anaphora, quotation, indirect report, and so on. Context of utterance is just a specific piece of what is normally called "social context" or situation or non-linguistic context; "context of utterance" is typically used to indirectly refer to the specific situation in which an utterance (a piece of a speech) is made and it is constituted by a list of the parameters necessary to interpret certain kinds of words. Cognitive context concerns the cognitive dimensions of beliefs, chunks of knowledge, assumptions, and is it sometimes referred to as "mental space" [41]; there is both an individual and a collective view of cognitive

\footnotetext{
${ }^{3}$ See Penco [88].

${ }^{4}$ Frege used "proper names" as a general word for expressions referring to an individual, included definite descriptions.

${ }^{5}$ Although "social context" is a wider general concept encompassing objects, actions, beliefs, institutions and everything you like.

๑) 2018 ISTE OpenScience - Published by ISTE Ltd. London, UK - openscience.fr 
context. In what follows we give some definitions used by philosophers following the path opened by Frege's remarks.

Having devoted much research on Frege's philosophical work, I became more and more aware how many Fregean suggestions lie below the surface of most debates on the concept of context and it may be of interest to keep in mind the original source (see $[86,90,93,95,96])$. But this is not the place to deepen this matter of history of ideas and in the following I will shortly present some alternatives on the role of context in three contemporary debates. But first I will give a short reminder to some of the main ways of treating the notion of context in philosophy of language after Frege, mainly concerning the notions (2) and (3). Notion (1) of linguistic context has been developed in linguistics in different theoretical settings that share a notion of "discourse context" (or "co-text"), and in Philosophy has raised many problems on the relations between sentences in indirect discourse (on Frege's perspective, see Kripke [65]).

The second Fregean idea (2) concerns the context in which an utterance is produced by a speaker (generally with an audience) and has been tipically defined as a set of parameters: time, location, speaker and possible world ${ }^{6}<\mathrm{t}, 1, \mathrm{~s}, \mathrm{w}>$. With his logic of demonstratives David Kaplan [60] had the great merit to introduce the double index (circumstances of evaluation and context of utterance) to treat indexicals in the logic tradition of Tarski, Carnap and Reichenbach. Expressions like personal pronouns ("I", "you", "she", "we"...), adverbs ("here", "there", "now"...) or demonstratives ("this", "that",...) have in common the property to have a fixed meaning, but what they refer to changes depending on the context of utterance ("I" refers to those speakers who use the pronoun, "you" refers to the different addressee, and so on). They are collectively called "indexicals", and represent the clearer case of context dependence. "I", "here" and "now" have the particular property to refer automatically, independently of the particular intention of the speaker and are called "pure indexicals". " "I am here now" expresses a contingent proposition that is not necessarily true, but it is true in all contexts of utterance. We will say that the sentence will be true at all contexts, but not in all circumstances of evaluation, that is a possible situation relative to which we evaluate whether the individual exists or the relevant property (in this case to be in a place at a time) is instantiated.

The notion of context of utterance raised a series of worries, starting with David Lewis [68: pp. 8586] according to whom we may put in the context everything that shifts, therefore not only time, location and speaker, but also audience, shared beliefs, standards of precision, states of mind, presuppositions. John Perry [63, 101, 103] distinguishes "narrow context" as the parameters of time, location and speaker sufficient for interpreting pure indexicals ("I", "here", "now") and "wide context" including other aspects like presuppositions, gestures or other sources of information, for interpreting other indexicals ${ }^{8}$. Kaplan's theory of indexicals has become a "standard" in semantic analysis and had survived all challenges received so far, but Kaplan's context is not the only context on the market.

${ }^{6}$ Possible world semantics originated by Kripke assumes different possible states of the world on which a sentence may be evaluated. A possible world is needed also in the context of utterance for the "double index" theory, where a sentence is evaluated at a context and in a circumstance of evaluation. The world of the context of utterance may be different from the possible world of the circumstance of evaluation. For instance, "I am here now" is a sentence that is true in all contexts of utterance, but not at all possible worlds.

${ }^{7}$ A particular property of the sentence "I am here now" is the following: it is true at all contexts of utterances, and therefore it is considered a case of analytic truth, that is true in virtue of meaning, as suggested by Gillian Russell [109]); but it is not true in all possible worlds (it is a contingent sentence, because I could have been elsewhere).

${ }^{8}$ Historical Remark: JohanVan Benthem suggested John Perry and John McCarthy to better define their respective notions of context: McCarthy [72, 73] and Perry [102] can be considered two parallel efforts to show different viewpoints on context from artificial intelligence and philosophy. For Perry [101] "narrow context" means the smaller set of parameters needed to interpret "pure indexicals" ("I", "now", "here"). I suggest that, for McCarthy [73], a narrow context, although not strictly defined, is always relative to a wider context where the narrow context can be "lifted". Therefore, also Perry's narrow context can be considered a McCarthy's context that can be lifted in a wider context, where the basic parameters are enriched by further parameters. See later on McCarthy's notion of context. 
The Fregean idea of presupposition (3) has been widely discussed until a new concept and a new framework of pragmatic presupposition emerged with the idea of context as the set of all presuppositions shared by the participants to a conversation: the "common ground" (Stalnaker [114, $115,116]$ ) is the background information that is taken for granted in a conversation. On this paradigm, under the idea of dynamic semantics, and in particular of update semantics proposed by Irene Heim [58], the meaning of a sentence is defined as context change potential, which is the capacity of changing the common ground (either restricting the set of possible worlds by giving a new information, or challenging the common ground with an information contrasting with some presupposed content). For instance, if I say "my sister stopped smoking" the participants to the conversation will update their beliefs to accommodate the new information presupposed by the sentence (if not yet present in the cognitive context), that is: I have a sister and my sister used to smoke. Therefore, they will exclude from the common grounds the possible worlds in which I have no sister or in which my sister never used to smoke; and any new information will restrict the set of possible worlds available to the hearers - in other words the common ground becomes more and more specific, depending on new information coming into the context of discourse.

Although there is a contrast between Kaplan's narrow context and Stalnaker's cognitive context, the background logical assumptions are both connected with model-theoretic semantics (possible worlds semantics). What changes is the perspective: on the one hand, we have Kaplan's point of view of semantics as abstracting from the cognitive perspective and giving a metaphysical "view from above" about the truth of the matter, independently of the agent's perspective ${ }^{9}$; on the other hand, works in Stalnaker's tradition take into account the different perspectives of different speakers. ${ }^{10}$

Saul Kripke [66] makes a distinction between "salient" or "active" context and "passive context". To me this distinction helps distinguishing on the one hand the original idea of "common ground", which seems a kind of passive general context as the set of shared beliefs we may be not actually aware of, and on the other hand the idea, developed by Christopher Gauker [50], for whom we need to define a "normative context" as the set of specific presuppositions needed to understand a specific conversation. Kripke's definition does not enter in the debate between Gauker and Stalnaker, but we certainly need to make a clear distinction between a descriptive aspect of cognitive context (what people actually share) and normative aspect of cognitive context (what people should share to understand a conversation). Here, experimental pragmatics might help in understanding and evaluating descriptive and normative theories of cognitive context (see Domaneschi et al. [30, 31, 32]).

In the following, I will trace the main lines of three contemporary debates centred on the notion of context. First, I will treat the general idea of generalizing Frege's context principle to the entire language, with the Davidsonian view of semantic holism. Then I will hint at the discussion on the boundaries between semantics and pragmatics that took the main attention of philosophers and linguists in the last two decades. A particular worry inside this debate concerns a specific topic in linguistics and philosophy of language, the topic of definite description: this will be our third case study. After a presentation of these three debates, I will try to give an indication of a framework in which these worries could be usefully framed.

\footnotetext{
${ }^{9}$ See for instance Kaplan [61]; for a criticism see Penco [97].

${ }^{10}$ Stalnaker [115] insists that "a number of ways in which what is presupposed may diverge from what is mutually known or believed". Indeed, we may presuppose something not only by believing it, but also by making a temporarily assumption, presuming that things are mutually believed although they are not, or even pretending thins are mutually believed when we know they are not. Domaneschi et al. [31] give some empirical result of these different attitudes connected to presuppositions. Penco [85] makes an analogous contrast between a metaphysical and a cognitive point of view exemplified by David Kaplan and John McCarthy, with the suggestion that Stalnaker's approach is too "heavy" for a proper cognitive assessment of speakers' capability (suggestion by Arlo Costa). 


\section{Between Semantic Molecularism and Semantic Holism}

Frege's context principle sounded so good that many philosophers developed it in a radical way, first of all, Ludwig Wittgenstein and Donald Davidson. Wittgenstein [130, 131] quoted the context principle both in the Tractatus Logico-Philosophicus, and in the Philosophical Investigations. In this later work, he claimed also that the meaning of a sentence depends on the language game in which it is embedded and suggested a holistic view, which much influenced Quine ([105: $\S 6]$ ) who quoted approvingly Wittgenstein's claim:

(4) "To understand a sentence means to understand a language. To understand a language means to be master of a technique" ([131: § 199)

Davidson [26], strictly following Quine, gave not only a suggestion but a declaration of meaning holism, against the idea that every expression of the language has its meaning atomistically given independently from all other pieces of the lexicon:

(5) "we can give the meaning of any sentence (or word) only by giving the meaning of every sentence (and word) in the language.

To better explain his methodological stance, he refers to Frege:

(6) "Frege said that only in the context of a sentence does a word have meaning; in the same vein, he might have added that only in the context of the language does a sentence (and therefore a word) have meaning"

At first sight this stance seems an update of the old idea of semantic fields in structuralistic semantic, according to which the organization of the lexicon changes from language to language depending on the structural relations among the lexical items of a language. But Davidson's extreme view has also strong counterintuitive consequences. Was Quine right in taking Wittgenstein on his side? Was Wittgenstein a supporter of holism like Davidson was? In a series of papers, Penco [87, 92, 94] follows Dummett in challenging Quine's and Davidson's holism, but accepting the basic idea that - against atomism - meaning of individual words cannot to be fixed independently of other words.

Michael Dummett, followed by Fodor and Lepore [44], challenges holism with a criticism analogous to the one posed by Frege to Locke. Dummett [36] [38] criticizes Quine's holism and his strong denial of a viable distinction between analytic and synthetic propositions, between what is true because of language and what is true because of facts. If we reject any distinction of the kind we arrive at a paradox: if the meaning of a word depends on the totality of beliefs of an individual, then we have no guarantee that two individuals may share the same meaning: we never know whether the disagreement concerns the meanings they gove to words or their beliefs. If two individuals cannot be assured to give the same meanings to the same expressions, then they can neither agree nor disagree. Hence communication becomes impossible. The apparent paradox is therefore as follows:

(7) if meaning is defined holistically, meanings cannot be used in communication: we cannot share the same meanings, therefore we cannot agree or disagree, hence communication become impossible

This paradox denounces the consequences of holism, but does not touches upon its reasons; however, it is sufficient to make a strong methodological stance against holism (Dummett [39: p. 21]; Fodor-Lepore [44], but see also Vignolo [125: pp. 84-88]). Locke would have answered that in the habit we tend to use the same ideas; Davidson [27] answers in similar way: given that we cannot assume that we share meanings a priori, we may think that use helps us to converge towards the same meanings. Therefore, we have to change our conception of communication: communication is not grounded on an a priori sharing of meanings (or decoding what is in the head of other people) but the activity of converging towards shared meaning, or, as Robert Brandom [17] puts it, in the process of communication we share the structure, not the content. 
Is this answer sufficient to address Dummett's worries? Certainly, in order to converge towards something shared you need to share something, at least to share some practical ability, for instance, the ability to recognize some inferences. We need a shared practice where we may manifest our understanding of an utterance, and what follows from it (the "inferential power" of a sentence). But Wittgenstein's legacy is not necessarily linked to semantic holism; as Dummett [37] stressed, his idea of language games is more apt to a view of language where some parts are needed to be learned before other parts, in a "molecularist" view of lexicon. Linguistic practice is composed of an unordered bunch of different language games, in which words hang together. The molecularist stance might be expressed as the idea that, if you share some sentence or proposition $p$, then you need to share some other propositions. However, not all your language is concerned, but only those propositions constitutive of the meaning of a word (you need to know what "to break" means in order to understand the concept of "fragile"):

(8) $\forall p \exists q(q \neq p \& \operatorname{Nec}(p$ is shared $\rightarrow q$ is shared $)$

Fodor and Lepore claim that, unless you give a class of privileged propositions, you have no idea of how to choose the proposition $q$ to be shared. Therefore this view implies the acceptance of some kind of dichotomy like the one rejected by Quine between "linguistic" and "factual" (or "analytic vs. synthetic"), although there are less compromising way to accept a distinction of the kind: for instance in classic artificial intelligence we have distinction between "definitional" and "assertional" components (Brachman and Schmolze [16] $)^{11}$ or, partly following Michael Dummett, we may distinguish between "meaning constitutive" and "derived" aspects of meaning (Cozzo [25] who develops an epistemological definition of meaning-constitutive properties that avoids the shortcomings of the analytic-synthetic distinction; see comments in Penco [89]). However, some authors have objected that this stance is too strong for a proper answer to the worries raised by Quine about any distinction that might take the place of the analytic-synthetic distinction. John Perry and Diego Marconi have therefore suggested a weak form of molecularism, later discussed in Penco [87, 91, 92]:

(9) $\forall p \operatorname{Nec}(p$ is shared $\rightarrow \exists q(q \neq p \& q$ is shared $)$

The scope of the quantifier changes the game: there is no more any privileged class of sentences necessarily shared, but necessarily, if we share some proposition $p$, there will be another proposition (another belief) $q$ that we share, although we cannot say which one in advance. This solution would avoid the a priori existence of a fixed set of "constitutive" aspects of meaning; what is necessary is that there is at least a shared belief in order to understand the interlocutor. This solution is very keen and has considered satisfying for Quinians, but it has the disadvantage of being a very weak stance in the sense that it oscillates between the stronger form of molecularism and holism. In fact, it is easy to see how the weak molecularist option oscillates between the strong molecularist one and the holistic one. On the one hand, you may ask which kinds of beliefs should be shared and you may answer (i) only the constitutive ones, and you are back to strong molecularism or (ii) any belief and you run the risk of falling again into a general holistic position where given a casual belief you may rely on another and so on until you reach in principle the entire language.

We are left with the last option; to insert an explicit mention of the context:

(10) $\forall p$ Nec $\exists c$ ( $p$ is shared $\rightarrow \exists q(q \neq p \& q$ is shared $)$

${ }^{11}$ The paper is a classical presentation of the KL-ONE systems in artificial intelligence. In KL-ONE there is a careful distinction between the description structure of the system and the assertions about co-reference, existence, etc. While the purely descriptional structure of concepts is fixed "all assertions are made relative to a Context and thus do not affect the (descriptive) taxonomy of generic knowledge" ([16]: p. 197). Quine and others might reply that a KL-ONE formalism represent the view point of the competence of an individual, a subjective competence of the author of that particular semantic network, where the definitional part is full of hidden choices based on beliefs and factual information. 
where " $c$ " means "context": not any proposition $q$ could be shared, but it is necessary that there is a context in which, if $p$ is shared then there is a proposition $q$ belonging to the "right" context in which a sentence is uttered. And, therefore, we are back to what we mean by "context". A possible answer is to interpret it in a way driven by the later Wittgenstein: a context is a language game where words are given meaning by the common practice of that game. This was the original idea held by Dummett in devising his molecularism, interpreted by Tennant ([122]: p. 44) as "a possible blend of globally separable local holisms". We may think of fragments of language where concepts are mutually dependents (like, for instance, colors). Akeel Bilgrami [12] suggested also another idea, similar to what is intended as "working context" in symbolic multi-contexts systems: we do not import everything we know or believe in every situation, but we import only those aspects of concepts that are useful. The entire "aggregate" of beliefs that a speaker attaches to an expression is not relevant at a local level: we never use all we know in a local situation, but what is needed.

The concept of context - as tool for analysing linguistic interaction - still oscillates between a cognitive aspect and an objective aspect. But definite problems help individuating a notion suitable for some specific purpose. A specific debate concerns how to define the truth conditional content of what is said with an assertion: how much context impinges on our intuitive understanding of the condition in which a sentence is true? In other words, should we rely exclusively on semantics (as interpretation of sentential components, relying on the narrow context for the saturation of indexicals) or should we rely on pragmatics (and therefore also on cognitive context of presupposition and other relevant extralinguistic information)? I will give a short summary on this debate in the next section.

\section{On the boundaries between semantics and pragmatics}

The question of boundaries between semantics and pragmatics has become a specific topic in the philosophical and linguistic discussion in the last two decades (see for instance, among many other collections, Szabò [121], Bianchi [11] and Domaneschi and Penco [33]). The most traditional attitude depends on Rudolf Carnap's view on the boundary. According to Carnap [20: p. 10], pure semantics is independent of pragmatics. In choosing the definitions and the rules of a semantics we are guided by pragmatic factors, that is considerations of a given language; "but this concerns only the motivations of our choice and has no bearing upon the correctness of the results of our analysis of the rules". It is as if pragmatics comes before semantics, giving some inputs and then leaving semantics to do its proper work: giving truth conditions of sentences. Here, if we take "context" as "narrow context", the only work pragmatics has to do is filling the parameters of the context with the right values (the referents of indexicals). We cannot tell for sure how much David Kaplan was actually influenced by the heritage of Carnap, but, certainly, there is a strong link between the author of Meaning and Necessity and the author of "Demonstratives" (and its technical apparatus of intensions).

Everything seemed to be settled with a clear-cut solution with the work of Paul Grice [54, 55], with the distinction between what is said (the truth-conditional content of a sentence in context) and what is implicated (what speakers intend to convey saying what they literally say, for example with implicatures). But, after a while, the Gricean concept itself of "what is said" went under strong attack from many sides. In fact, if what is said is the truth-conditional content, how can we give the truth conditions of many sentences without making some appeal to pragmatic factors?

Examples $^{12}$ run from cases of incompleteness or indeterminacy of different kinds:

(11) Ann is ready

${ }^{12}$ I here give a simpler and unifying presentation of the different "arguments" used by contextualists: context shifting arguments, incompleteness argument, inappropriateness arguments, indeterminacy arguments (see also a nice presentation in Borg [13]). At the end of the story every argument can be represented as a kind of indeterminacy. The example of the painted leaves, originally from Travis [123], has been widely discussed in the literature. The phenomenology of examples is really wide, and point to a general disease without a proper unifying answer. 
(12) John cut the grass

(13) I didn't have my breakfast

(14) Ann is tall

(15) The leaves are green

Under which conditions can we decide whether these kinds of sentences may be true or false? "Ann is ready" seems incomplete: it has no truth conditions unless it is specified what is she ready for: for going out? for the exam? for eating? Analogously "I didn't have my breakfast" has an intuitive truth condition as "I didn't have breakfast today" that is not derivable by the syntax of the sentence. Also "Ann is tall" is completely indeterminate, because it may be true in respect of the reference class of her companions and false in respect of the average high of basketball players. Analogously "The leaves are green" - said of leafs painted in green - seems to be true for a painter and false for a botanist. Compositionality of "literal" word meaning seems not sufficient to understand what a speaker is saying.

The process of interpreting sentences (11)-(15) depends on the context in which we understand for what A is ready, with which means John cut what kind of grass, whether the leaves are painted in green or are originally green, and so on. Depending on the context you may have different truth conditions of those sentences. In all these cases the notion of context, although not explicitly stated, is the context of dialogue or context of conversation, where different purposes or reference classes or viewpoints are relevant (see Corazza [24]). We may also speak of "wide context" as the context of utterance enriched with other parameters or relevant information, but it is not clear where these parameters are taken from.

To answer this worry, Recanati $[106,107]$ distinguishes among primary pragmatic processes those that are mandatory (resolution of ambiguities and saturation of indexicals) and those that are optional and consist of different kinds of modulation: enrichment, transfer, broadening and narrowing of an expression. Carston $[21,22,23]$ prefers to speak of explicature as the inferential pragmatic process that enriches the incomplete expressions in a sentence in order to produce a truth-conditional evaluable proposition. There are differences between Recanati and Carston especially concerning the automatic or inferential aspect of the enrichment of the sentence ${ }^{13}$ however, both give a fundamental role to pragmatics - to information taken from wide context, including general knowledge of the world - in order to have a truth-conditional propositional content. With a radical move, Recanati [107] speaks of truth-conditional pragmatics and challenges the standard model theoretical semantics that relies on fixed literal meanings. He asks for a general rethinking on the notion of truth conditions in natural language, where under-determination of meaning is the standard (differently from mathematical language where meanings are fixed). We are in front of pragmatic cognitive processes intended as "top-down" procedures that are partly free from syntactic aspects.

On the opposite side, often adhering more strictly to Grice's original view or with minor adjustments, many authors give a stricter connection with syntactic structure, in a more "bottom-up" model, which requires no further pragmatic insertion in semantics besides the saturation of indexicals. They keep a more standard "semantic" view of what is said, of the truth conditional content of our sentences: one of the first reactions came from a seminal paper ${ }^{14}$ by Kent Bach [5], who rejects Carston's and Recanati's proposals insisting that there is a level of semantic information - that can be

${ }^{13}$ Recanati's primary pragmatic processes are automatic, while secondary pragmatic processes are mostly inferential or connected with frames or stereotypes. The main debate with Relevance Theory concerns the measure of inferential processes, which are more pervasive from the viewpoint of Relevance Theory.

${ }^{14}$ In Bach [5] the main contention is against the rigidity of Grice's distinction between what is said and what is meant and the attempt to find something in between: the impliciture, that is what is said from a pragmatic point of view. I will not discuss this aspect here.

๑) 2018 ISTE OpenScience - Published by ISTE Ltd. London, UK - openscience.fr 
also not completely propositional - but still has a role in semantic explanation. Indeed "Ann is ready" without any explicature, sounds not propositional, yet it is certainly something we may use in indirect disquotational reports, differently from sentences with indexicals. I cannot report "I am tired" said by John with, "John said that I am tired", while I can literally report "Ann is ready" said by John as "John said that Ann is ready" (the argument became famous as "inter contextual disquotational indirect report"). The mistake of contextualists, Bach claims, is to confound what is given by the context (the saturation of indexicals) and what is given in the context (everything else).

In Bach's idea of semantic information given by sentences like "Ann is ready," there are two aspects: something minimal and something incomplete. While the latter aspect is partly shared by contextualists, minimalists like Ernst Lepore and Emma Borg develop the former (the idea of something minimal). According to minimalists like Cappelen and Lepore [19] and Borg [14], only indexicals have a special place in semantics, forming the "Basic Set" of the only really contextdependent expressions. All other expressions that seem to be context-dependent, like "Ann is ready" express minimal propositions that are "available to provide the literal meaning of sentences" (Borg [13: p. 341]. The idea of "minimal content" has been also developed by relativist positions, developed after MacFarlane [77], which claim that minimal propositions can be true or false depending on different assessments, still keeping the same (minimal) truth conditional content.

One of the main contentions of the traditional point of view in semantics, shared by Kent Bach [6], Michael Devitt [29] and Stephen Neale [82], among others, is that contextualists make confusion between metaphysics and epistemology:

- Metaphysics of meaning concerns the constitution of meaning, in a "view from above", and depends on the intentions of the speaker.

- Epistemology of meaning deals with the process of understanding and concerns the point of view of the hearer and the problem of a communication theory.

But isn't this general contraposition just a new rendering of the old Carnapian view of semantics, determined by the early interest in mathematical logic, where no concern on the point of view of the hearer was relevant? Actually, even direct reference theorists like Donnellan took in the right consideration the attitude of speakers towards the attitude of the hearer; it is worth quoting a passage by Donnellan on this regard:

In the analysis of meaning given by Grice, a speaker means something by an utterance when he has a certain complex kind of intention involving recognition on the part of his audience of his intention. And what the speaker means is determined by the content of that intention. Whether he can form that intention, however, may depend upon what expectations he has about his audience and their ability to grasp his intention. It does not follow, then, from this analysis that speakers might, out of the blue, mean anything at all by any utterance. And the existence of an established practice may be usually required for speakers to have the right expectations. (Donnellan [35: p. 209])

It seems that Donnellan here presents an "epistemological" worry, linked to the speaker's and the hearer's cognitive limitations, abandoning the too strong separation of the roles of speakers and hearers (on this see also Domaneschi-Penco [34] and Penco [98]). The main problem of the debate becomes: shall we consider a sharp separation of metaphysics and epistemology a useful guide to a proper treatment of semantics or shall we look for some insertion of epistemological aspect to help semantics to do its proper job when concerning natural language? Maybe we need to do in semantics what Herbert Simon did in economics, recognizing a proper role of the limited or bounded rationality of the actual speakers. Coherently with this point, there is also a general worry about the concept of "minimal" proposition concerning its actual function in semantic representation: which role does it fulfil? It is true that syntactically we may produce a correct report like "john said that she is ready", but where in the actual world shall we sensibly use such reports? It is reasonable to think that we really use 
it only as relying on some anaphoric or elliptical phenomenon, or directly implying an explicature. Therefore, the problem with minimal content is whether it may perform a real function in interpreting truth conditions and many criticisms have put this notion in question.

Assuming the point of view of contextualists, on the other hand, we have to face the problem of general under-determination of meaning - with the risk of over-generation of meanings (against Grice's desideratum that meanings should not be multiplied beyond necessity). If meaning depends on context and we want to avoid a generalized semantic holism, we need (i) some restriction of the general idea of context-dependence, (ii) some general explanation of the process of enrichment of explicature that is more than a description of the phenomena, (iii) some way to preserve compositionality of meaning, which is a mandatory principle in semantics.

This last topic has partially answered in different ways by Unsteinsson [124] and Pagin [84], and I will not discuss it further. The other two problems seem to find a possible solution in the suggestion given by Bach [5] to consider meaning as connected to a template to be enriched or a frame with slots to be filled depending on context and relevant information (this idea was anticipated, up to a point, by Marvin Minsky [75, 76], and Charles Fillmore [43]: each lexical item can be considered as linked to a complex structure, a template with slots that are normally are filled by default, but may be changed in front of new information). Carston [21: p. 226] widely relies on the idea of "template" that must be "enriched" to be properly interpreted. However, a generalization of the template solution to every kind of phrase may pose new problems. A typical case of application of the "template" solution is the problem of incomplete definite descriptions, but here the solution may present more difficulties than it appears. I will take this case as a last example of debates not yet solved in the contemporary discussion on contextual dependence.

\section{Definite descriptions and the "explicit"/“implicit" divide}

One of the most widely discussed problem in the philosophy of language is the topic of definite descriptions (see for instance [40] [69] [81] [104] [108] [112] [120]): descriptions that are preceded by a definite article and are therefore supposed to pick a unique individual, following the classical Russell's theory of descriptions ("the present King of France is bald" means that there is a unique present King of France and that he is bald; an apparent falsity). A debated topic in this area is the problem of "incomplete descriptions" like "the table", which is apparently "incomplete" because it is not descriptively sufficient to pick a unique table (this was one of the main criticism of Russel's theory). Neale [79] labelled "implicit" and "explicit" the two main approaches to incomplete descriptions (and quantified NPs in general). The explicit approach requires completing the template or matrix of the description to make the description to denote just one thing, as for instance "the blue table in front of you on the right corner of the room we are in" (you may remark that we use also indexicals like "in front of you" or "the room we are in", like in Russell's example "the present King of France", that refers to the time of the utterance). The completion may be done with free enrichment or with more constrained means linked to some syntactic aspects (resp. Carston [21], Neale [80]). The implicit approach assumes a contextual restriction of the domain of quantification and therefore, in the case there is a unique table in the relevant context, the definite description picks that unique table. The implicit approach has been differently defended and developed by many philosophers and linguists: while a first "simple" view would restrict the domain to a part of the world, for instance a situation, as suggested by Barwise and Perry [9], Westerståhl [126: p. 49] remarks that we are not bound to use a unique context set as domain, given that different quantifiers in the same sentences may be interpreted relatively to different domains, an assumption developed by Staney and Williamson [119]. Stanley and Szabò [118], Stanley [117] and others insist on the necessity of linking any possible completion with hidden or aphonic variables in the syntax (a wider discussion on the aphonic elements in language is given by Neale [83]). 
Here, however, we do not want to discuss the problem of the requirement of covert variables, or of aphonic elements in the logical form. We want instead discuss the idea suggested by Neale [78] according to whom the implicit and the explicit approach might turn out to be notational variants of one another. Neale's hinted equivalence has never been overtly sustained nor rejected. The point made by Neale is the following: on the one hand a quantifier or Determinant $[\Delta \mathrm{x}: \phi(\mathrm{x})]$ might be completed with some further description "G" into $[\Delta \mathrm{x}: \phi(\mathrm{x})] \& \psi(\mathrm{x})]$ or restricted to a contextually relevant domain of quantification $\mathrm{D}$, as $[\Delta \mathrm{x}: \phi(\mathrm{x})]_{\mathrm{D}}$ or $\left[\Delta \mathrm{x}_{\mathrm{D}}: \phi(\mathrm{x})\right]$. For instance, "the $\mathrm{x}$ : Table $\mathrm{x}$ " may become "the $\mathrm{x}$ : Table $\mathrm{x} \&$ Placed-in-this-room $\mathrm{x}$ " or "the $\mathrm{x}$ that is a table in the domain of quantification of this room". Neale [78: p. 289] gives the following definition to show that these two approaches can be viewed as notational variants of one another:

"To convert an implicit $\left[\Delta \mathrm{x}_{\mathrm{D}}: \phi(\mathrm{x})\right]\left(\right.$ or $\left.[\Delta \mathrm{x}: \phi(\mathrm{x})]_{\mathrm{D}}\right)$ into something explicit, just strip off the $\mathrm{D}$ representing the restricted domain, form a formula $x \in \mathrm{D}$ and conjoin it to the original matrix $\phi(\mathrm{x})$ to produce the 'complete' quantifier $[\Delta \mathrm{x}: \phi(\mathrm{x})] \& \mathrm{x} \in \mathrm{D}]$. To convert an explicit $[\Delta \mathrm{x}: \phi(\mathrm{x})] \& \psi(\mathrm{x})]$ into something implicit, just strip off the second conjunct of the matrix, form a set description $\{\mathrm{y}: \psi(\mathrm{y})\}$ and append this to the quantifier to signify the restricted domain of quantification."

The argument seems very clear (up to a point), but logical analysis is not enough to help clarifying what comes first in the order of explanation and we are left with further work concerning the psychological plausibility of the two approaches. There are at least two reasons for which the implicit approach and the explicit approach cannot turn out to be notational variants of one another:

(1) In order to give a specific descriptions in the explicit approach, we have to specify the elements of the context to which the descriptions apply; therefore, in the explicit approach, we have a double work: specifying the context and specifying the properties belonging to the elements of the context; but in specifying the context we already specify an intended domain, performing therefore at the same time what is the main characteristic of the implicit approach.

(2) The explicit approach seems to work as the last resource to make the context clear to the hearer who does not understand; it is, therefore, an aspect of a theory of communication: when the hearer does not get the context right, she needs a supplementation from the speaker who has to specify a way among many to get the referent right. However, as already remarked by Wettstein [127] for referential descriptions, the speaker needs not entertaining these specifications. In fact, the speaker does not need to represent an enriched description because it is enough she relies on the elements of the context she is aware of.

The implicit approach seems to be the most reasonable explanation of the cognitive processing of what is expressed by a speaker. When I refer to something with an incomplete definite description like "the table", I don't need to "enrich" my description; I may think, just for a reminder, "Oh I have to put the book on the table" and I need nothing more than having in mind the setting of the relevant situation. Here domain restriction comes from the awareness of the situation in which the speaker stands, and can be triggered by the incomplete definite description ${ }^{15}$, on the assumption that the speaker is not dealing with whichever table in the world, but with a specific table, given in the context of the utterance.

However, it is not only a question of cognitive processing that tends to give more relevance to the implicit approach. There is also an epistemological aspect of the agreement of speakers about the kind

\footnotetext{
${ }^{15}$ Stanley-Szabò [118] and Stanley [117] are at the origin of indexicalism that requires a domain restriction bounded by quantifiers; following Neale [79, 80], Penco [94, 98] assumes that a definite description even if used referentially, has a quantified structure and therefore it can be considered a typical case of triggering a requirement for the restriction of the domain. Criticisms like Cappelen and Lepore [19] don't take into account that what is hidden is not a piece of lexicon, but a parameter.

๑) 2018 ISTE OpenScience - Published by ISTE Ltd. London, UK - openscience.fr

Page | 11
} 
of approximation needed to exchange information. Epistemological contextualists like Williamson [128] have widely insisted on the context-dependent way to fix the kind of precision with which we attribute knowledge ${ }^{16}$. This feature is relevant also when dealing with the meaning of definite descriptions in everyday conversation. In using definite descriptions, we often rely on a default agreement on the loose character of our descriptions; most of the time we are not looking for precision, but for efficiency, and where efficiency is traded with the risk of error, errors in the details of the description become irrelevant if the main core of the description works. When in a party I say:

(16) "The man drinking champagne in the corner is a friend of mine."

I don't care what that man is really drinking, but I use the description to select him among others. A philosopher devoted to precision interprets [the $\mathrm{x}: \mathrm{F}(\mathrm{x})$ ] as "the unique $x$ that has the property F"; a speaker in normal situation means [the $\mathrm{x}: \mathrm{F}(\mathrm{x})$ ] as "the $x$ that it seems reasonable to describe as F", with the proviso: "but I don't care if eventually, he is not $\mathrm{F}$; what counts is that you get the individual I was justified in thinking that their appearing is F" (see Penco [94, 98]; see also Bach [4] and Jaszczolt [59]).

If we want to represent the conventional linguistic behaviour of efficient dialogue, then we need to recognize this aspect of default agreement and default reasoning in everyday conversation. This feature is different from the typical processes of either Recanati's modulation or Carston's explicature; it is a specific feature given by the context's epistemological restriction: are we in a context with high level of precision like a legal or scientific context or in a general, relaxed, context of everyday conversation? This feature is partly coherent with the idea of "loose talk" presented by Relevance Theorists. According to Sperber and Wilson [113: p. 165], loose talk motivated by the pursuit of relevance: achieving the greatest cognitive effect with the least effort. If the cognitive effect I want to pursue is to make the hearer refer to what I have in mind I would never say something like

(17) "The adult male salient in the scene who seems to me, although I don't know for certain, to drink champagne, given that we are in a party and he is drinking from a glass that seems what is normally used for champagne, but if he is drinking something else I don't care".

On the contrary, I will give it for granted that we all assume the looseness and approximation of our inaccurate descriptions and that we intend them just a short way to get the referent right, given the normal amount of information available at the moment. It would be different if I were a policeman required to check whether somebody is drinking an alcoholic drink when not allowed.

Speakers and hearers, sharing a common situation, conventionally share a lot of basic assumptions of what is relevant to expressing and understanding a sentence in context. If a speaker intends to refer to some individual in the context, she will choose the best means to avoid misunderstandings, granting a lot of epistemological assumptions we normally implicitly do. Maybe only philosophers and policemen might react asking: "Are you really sure he is drinking champagne"? In fact, their concern may lie not in understanding the purpose of the conversation, but only their peculiar theoretical or practical interests. But philosophers of language, differently from policemen, should also try to explain the convention of using inaccurate descriptions to get the referents right. ${ }^{17}$

\footnotetext{
${ }^{16}$ A clear anticipation of this aspect of meaning-approximation given by the purpose of the conversation is given by Austin when he asks about the truth or falsity of sentences like "the galaxy is a shape of a fried egg" or "France is hexagonal". Both are false on a strict scientific ground in astronomy or geography, but it is difficult to deny that both are true and useful in the context of everyday conversation. As Austin [3: p. 130] claims, a statement "fits the facts always more or less loosely, in different ways on different occasions for different intents and purposes"

${ }^{17}$ On a development of this aspect see Penco [98], Benzi and Penco [11]. On a general phenomenology of the idea of inaccurate descriptions see also Korta and Perry [62,63], who however seem to keep a more traditional Kripkean stance on the matter, following Kripke [64]. 


\section{Suggestion from Computer Science: Contexts as Filters}

We have seen three open debates in philosophy all centred on the notion(s) of context. In the first debate, we found that one main problem with Davidson's proposal was the absence of any restriction to the under-determination of meaning and we suggested that context dependence would be a restriction to this effect. Either a holistic or a molecularistic stance needs a restriction to local contexts. The outcome of the second debate was a generalisation of the idea of under-determination of meaning: here the problem is to find which strategies permit to solve meaning under-determination in context and we have seen that different alternative proposals are at work in semantics. The third, more specific debate, gave a first example on how the meaning and the reference of an expression are constrained by different features of the context, either restriction of the intended domain or levels of approximation required for the purpose of the conversation. We don't have to mistake purpose with meaning, but purposes may affect the meanings we give to our words.

How to deal with meaning under-determination and with reference assignment in context? Shall we continuously enlarge the number of contextual parameters? As Pagin [84: p.23] reasonably said, "it is not likely that a definitive list of potentially relevant context features can be produced". We cannot just continuously enrich the set of relevant parameters of context (or the parameters of the circumstances of evaluation) and we need a new start, a more general framework. A suggestion comes from symbolic artificial intelligence, ${ }^{18}$ a suggestion that interacts with many ideas in linguistics and philosophy. What struck me in artificial intelligence, before the development of neuroscience and big data, were two aspects that I find attuned to the Wittgensteinian viewpoint, which I described above as a generalization of Frege's context principle. Wittgenstein wanted to study how language works in the context of situations, with their aims and activities - calling "language games" these primitive ways of using language in context; language itself may be thought as a network of different language games. Basically, artificial intelligence developed both ideas, the idea of studying language in isolated chunks of knowledge (in the paradigm of toy worlds or of frames and scripts) and the idea of studying the relations among different contexts (in contextual reasoning). I will give a short reminder to these two main lines of thought, as something deeply connected with the problems philosophy of language attempts to solve.

Not only many linguists and philosophers but also many computer scientists share the idea that, in order to study how language works, we need to study specific kinds of situations in which we use words. ${ }^{19}$ A first example is the project of toy-worlds or blocks-worlds in the seventies: Winograd [129] created SHRDLU twenty years after the publications of Wittgenstein Philosophical Investigations. No reference to Wittgenstein in SHRDLU but a simple idea: in devising SHRDLU Winograd realized that (i) instead of trying a program for every purpose it would be better to represent a particular situation in all the details (ii) to define the meaning of the words we need to define the way in which words are used, to give the procedures activated by different linguistic actions (assertions, commands, questions) that produce the correct answers in the robot that interacts with the speaker inside the toy-world.

Two other examples come from Marvin Minsky and Charles Fillmore. Minsky [75] proposed the idea of concepts as frames (with slots with default values), explicitly recalling Wittgenstein's ideas of

${ }^{18}$ Abu-Hakima and Brézillon [57] distinguish two different kinds of viewpoints in AI: the engineering viewpoint (McCarthy, Giunchiglia, and all logicians) and the cognitive viewpoint (people working mainly in communication). Actually, they also suggested that different uses of the notion of context in different disciplines make multidisciplinary interaction difficult. However, a convergence is possible: we have seen that there is a dynamic aspect in the development of dialogue context in dynamic semantics, which tends to encounter the needs of communication theory, while a more static aspect is given by the context of utterance that relies of basic elements of the situation in which an utterance is made (speaker, time, location and possibly other relevant aspects of the situation).

${ }^{19}$ The most famous example in philosophy is Situational semantics proposed by Barwise and Perry [9], with a detachment from possible worlds semantics: when in possible worlds we have ideally a truth value for every possible proposition, in situations we are concerned with a limited part of reality. 
family resemblance concepts. Following this lead, Schank and Abelson [111] proposed the idea of concepts as scripts as schematic kinds of actions hierarchically ordered and inheriting from the higher kind - for instance a bar inherits the properties of a commercial enterprise, which requires at least an exchange between a seller and a buyer, and has some more specific features (for an update on this line of research see Delogu, Drenhaus and Crocker [28]). Fillmore [42] notoriously developed frame semantics, where he insisted on the idea that a linguistic item activates a frame with a series of slots, some of which mandatory and others optional and ready to be filled (the distinction between "core" and "peripheral" frame elements approximates this distinction, but the expression of some core elements is not always necessarily expressed, like in an order "please, leave the room": the unexpressed core element is the subject to which the order is given). The work on frame semantics has been developed in artificial intelligence as "Framenet" (see Fillmore and Baker [43]) and is coherent with psychological data and results as widely discussed by Barsalou [8] on the way we learn concepts in context (see also Yeh and Barsalou [132], where context is another term for background situation, and Lebois et al. [67] for a general assessment). When we learn the use of a word, we learn something more than a definition; we learn its possibility of combination with other concepts and chunks of knowledge that come with the use of the word. Actually, we implicitly learn to manage an ontology that is embedded in the lexicon and helps adapting the default meanings to specific situations, given the other surrounding lexical items, as widely discussed by Asher [1], Asher and Lascarides [2], Balletta [7] Jaszczolt [59]). These kinds of studies suggest the idea of a "rich" aspect of the lexicon that can be connected with hidden structures with variables (slots) that either need to be filled (maybe by default), or may remain empty if not required, leaving a certain amount of approximation in the information presented by the speaker.

All these attempts, and in particular the development of toy-worlds, point to a general analysis of language as an interconnected network of language games; we may think of reconstructing language individuating different toy-worlds, or different partitions of the world depending on aims and kinds of activities. Apparently, the main problem here concerns the relations among different language games or contexts: how are they connected? This problem has found a first attempt of explanation in the project of contextual reasoning ${ }^{20}$ and of multi-context theories, developed by McCarthy $[71,72,73$, 74] and Giunchiglia [52, 53], with the notion of "lifting rules" (McCarthy) and "bridge rules" (Giunchiglia) that permit to import what has been derived in a context into another context, or to connect contexts at the same level. Here the idea of context is slightly different from the ones presented in the first section of this paper, because it permits to have contexts as representations of particular situations possibly using different languages, something normally not considered in the concept of context in philosophy so far. But in this respect we have another analogy with the Wittgensteinian view of natural language as a network of different language games: language games are different and not necessarily hierarchically ordered, yet they may interact each other. What is needed, therefore, it the explanation of the rules that permits navigate across them. Multi context theories defines operations on contexts, like entering/exiting a context (making the parameters explicit or implicit), importing a context inside another context, giving the rules that permit or forbid the passage from a context to another ${ }^{21}$. This kind of work should bring about a better awareness of what can be called "contextual rules", that is, rules that work on contexts and across contexts: when we learn using language, besides learning some central language games, we learn how to enter and exit a context and which rules permit us to navigate across contexts. These rules amount to a proper strategy, whose apparent "mystery" we have to explain, against Davidson retreat ${ }^{22}$.

\footnotetext{
${ }^{20}$ Multi context theories were framed inside the project of common-sense reasoning, and - given that semantic-lexical competence is first of all inferential competence, as Marconi [70] shows - we may take contextual reasoning as the leading strategy for representing lexical competence (somehow following the development of semantic networks).

${ }^{21}$ A slightly different view is given in philosophy by the idea of contexts that "points" to other contexts, as given in Gauker [51]; on a different version of contextual reasoning and of lifting rules see also the discussion of different epistemic contexts by Bouchard [15].

${ }^{22}$ Davidson [26] famously said: "strategy is a gracious word for the mysterious process through which a speaker or a (c) 2018 ISTE OpenScience - Published by ISTE Ltd. London, UK - openscience.fr Page | 14
} 
How can these two kinds of suggestions help facing the problem of under-determination of meaning and of reference we have seen emerging in our three case studies? In facing the problem of meaning underdetermination we have seen a proliferation of different means for representing context dependence as triggered by linguistic aspects and requiring different kinds of procedures of "recovering" meaning in context: narrowing, broadening, transfer, or explicatures or implicitures, binding "and so on" (respectively, Recanati, [106, 107], Carston [21], Bach [5], Stanley [117]). What have all these procedures in common? They all are pointing to a main role of context, the role of filtering the relevant information. But this is exactly the fundamental tenet of multi-context theories that requires a definition of pragmatic or contextual rules, which concern, respectively, (1) partiality, (2) granularity and (3) perspective. This suggestion - originally given by Benerecetti et al. [10] and partly followed by Guha and McCarthy [56 $]^{23}$ and Penco and Vignolo [99] - points toward the idea of pragmatic competence. In what follows I give some suggestion on how the role of pragmatic competence can be conceived and how it impinges on semantics proper. Pragmatic competence is contextual competence, it is the ability to enter a context, to change context, to import contexts, essentially to navigate across contexts. Representing this ability is representing the different operations that permit to fill the mandatory or non-mandatory slots of our frames, and that permit to accept an interpretation of a sentence even if not completely specified (analogously to the hints given by Perry on different levels of truth conditions).

\section{Underdetermination and pragmatic competence}

The problem of underdetermination has many facets but classical artificial intelligence taught us something relevant: we have strategies to face underdetermination both at lexical (conceptual) level and at sentential level in producing and interpreting natural language. The general problem of meaning underdetermination can be nicely framed if we think of context as what does the work of filtering meanings and references, through different kinds of procedures. The above mentioned three kinds of abilities for filtering the right meanings and referents in context may be represented as a set of different procedures, constituting a framework in which to treat different aspects of underdetermination.

(1) Partiality or Domain Restriction is a property of contexts that points to the ability to get the relevant objects in the domain (including the referents of definite descriptions and other quantified phrases). Entering a context - be it a context of utterance or a discourse context - we need to identify the elements of the domain, objects, individuals and classes on which we quantify. Many linguistic features, from informative presuppositions to variable binding, help defining domain restrictions. The interpretation of a quantified sentence is almost always referring to a specific context, and the wide use of covert variables (Neale [83]) may help treating most cases of domain restrictions (Stanley [117]). Eventually, most domain restrictions will require an indexical or a demonstrative, given that there in no way to precisely and completely subclassify the universal domain (as stressed by Gauker [51]).

(2) Approximation or Looseness is a property of contexts that points to the ability of deciding the level of granularity of the descriptive content depending on the goal. Entering a discourse, we always have to decide which level of approximation we should use in our description depending on the goal of the conversation. What goes under the tag of "Under-determination of meaning" is mostly related to the ability to avoid filling more or less slots of a concept or frame. ${ }^{24}$ Every lexical item can be connected with

hearer uses what he knows in advance plus the data of the moment to produce a passing [local] theory".

${ }^{23}$ Guha and McCarthy [56] suggested inserting two further elements: Ambiguity and Fiction. I didn't put ambiguity only because disambiguation is typically considered as something to be done in a "pre-semantic context", as Perry [101] would say: a mere linguistic/syntactic adjustment of ambiguous phrases or sentences is a necessary step before getting to semantic evaluation, with saturation of indexicals and definition of what is said. However, we may well consider disambiguation as part of the filtering work made by the context given that sometimes a syntactic ambiguity may be resolved by extra-linguistic information (the example given by Perry "I saw her duck under the table" may be easily resolved in seeing a scene with a duck or with a woman hiding under a table). About fiction the debate is so hot in philosophy now that I don't' want to enter the discussion here.

${ }^{24}$ When Stanley [117], in a criticism against Relevance Theory, says that there is no covert variable for "manner of eating" connected to "eat" he should have said that there is no mandatory covert variable. The lexical unit "eat" 
a rich frame, but we do not need to fill all the slots. Speakers assume that hearers may easily leave some slots empty, for instance in "John cut the grass", we may use the verb "to cut" - separating drastically parts of something - without filling the slot of which tool is used (a knife, a pair of scissors, a mower...) or we may use "grass" without specifying exactly which kind of material we are referring to (a blade of grass, a field, a piece of artificial turf...); we leave the truth conditions fixed, although we don't know exactly what some words refer to and wait for the development of the conversation. In this case it is enough that truth conditions of a nonspecific content make a partition of worlds where the sentence is true and where it is false. We have to distinguish carefully between underdetermination and non-specificity, as Sainsbury [110] stresses. We should therefore carefully distinguish mandatory and not mandatory hidden variables: while in some cases underdetermination requires completion (e.g. comparatives like "tall", where we need to have a reference class), in other cases there are standards of acceptance of not specific contents. In the latter case, the ontology implicit in the lexicon may help disambiguating uses like metonymy or transfer (the ham sandwich left without paying). These different kinds of looseness are a fundamental requirement of a contextual filter and need to be developed as a proper field study.

(3) Viewpoints: is a property of contexts that points to the ability of coordinating different viewpoints given by indexicals and presuppositions. We check the different viewpoints in the context (starting with indexicals and with pointers to other cognitive contexts). Besides the work of Kaplan, we have also interesting suggestions for the compatibility of different viewpoints in local model semantics (Giunchiglia-Ghidini [53]) and in other philosophical environment like Brandom's analytic pragmatism [17] or Gauker's contexts pointing to other contexts in indirect speech [51] in a perspective that seems compatible with many suggestions of multi context theories.

How should we represent these abilities? Which kind of procedures can we define (lifting rules, binding processes, etc.)? Certainly, they are not just question of psychology, but are part of linguistic conventions. Should they be ordered, reasonably, in a sequential order? ${ }^{25}$ Can we suppose that we first need to define the domain, then the level of approximation and then check different viewpoints? Only empirical research may help to check the psychological plausibility of the connections among these abilities: we may study which choices a speaker makes when entering a context, and which assumptions she makes using the three abilities given above.

The present paper apparently hides many contrasts among different stances, and it is not intended as an alternative to specific theories; whether the filtering work done by contextual competence will define the procedures needed to give the referents of semantic analysis or will directly enter the so called "pragmatic truth conditions" is a question still undecided. My aim is to call the attention towards a unifying framework, contributing to the definition of what is meant by "pragmatic competence", that is, contextual competence or the ability to enter a context and to navigate among contexts. The work to be done on these abilities may have consequences in different kinds of theories.

\section{References}

[1] Asher N., Lexical meaning in context. A web of words, Cambridge: Cambridge University Press, 2011.

[2] Asher N., Lascarides A., Logics of conversation. Cambridge University Press, Cambridge, 2003.

[3] Austin J.L. Philosophical Papers, Oxford: Clarendon Press, 1961.

[4] Bach K., "Default Reasoning: jumping to conclusions and knowing when to think twice", in Pacific Philosophical Quartely 65, pp. 37-58, 1984.

[5] Bach K., "You don’t say”, Synthese 128, pp. 15-44, 2001.

certainly is connected with a frame where it is possible to specify a manner of eating; the fact that it is not mandatory helps understanding not under-determination, but under-specification, which is a plain and normal linguistic phenomenon.

25 For the problem of referential descriptions, the suggestion is that first we select the relevant domain and, by approximation, we try to get the intended referent depending of the correct level of looseness of the description and then take into consideration the different viewpoints of speakers, hearers and reporters. It is an empirical question whether the attributive use of a definite description prompts out only after a referential use fails to be reasonably acceptable and there has been a great empirical research on the matter, with still uncertain results.

(c) 2018 ISTE OpenScience - Published by ISTE Ltd. London, UK - openscience.fr 
[6] Bach K., "The lure of linguistification". In: Domaneschi F. and Penco C. (Eds.) What is said and what is not. Stanford: CSLI publication, pp. 87-98, 2013

[7] Balletta S. "Ontology Based Semantics", in Proceedings of the Workshop on Contexts in Philosophy, CEUR Proceedings, vol 1845, pp. 6-19, 2017.

[8] Barsalou L.W., "Situated conceptualization: theory and application", In: Y. Coello \& M. H. Fischer (Eds.), Foundations of Embodied Cognition. Psychology Press: East Sussex, 2015.

[9] Barwise J., Perry J., Situations and Attitudes. Cambridge, MA: MIT Press/Bradford Books, 1983.

[10] Benerecetti M., Bouquet P., Ghidini C., "Contextual Reasoning Distilled", Journal of Theoretical and Experimental Artificial Intelligence, 12(3), pp. 279- 305, 2000.

[11] Bianchi (ed.) The Semantics/Pragmatics Distinction, 45-64, Stanford, CSLI Publication, 2004.

[12] Bilgrami A., Meaning and Belief, Oxford, Blackwell, 1992.

[13] Borg E., "Minimalism versus Contextualism in Semantics". In: G. Preyer and G. Peter (eds.) Context Sensitivity and Minimalism, Oxford: Oxford University Press, 2007.

[14] Borg E., Pursuing Meaning. Oxford, Oxford University Press, 2012.

[15] Bouchard Y., "Reasoning in Epistemic Contexts" in P. Brézillon, C. Penco, R. Turner (Eds.), $10^{\text {th }}$ Congress on Modeling and Using Context (CONTEXT-17), LNAI, 2017.

[16] Brachman R.J., Schmolze J.G., "An overview of the KL-ONE Knowledge Representation System" in Cognitive Science 9, pp. 171-2016, 1985.

[17] Brandom R., Making it Explicit, In: Harvard U.P., Cambridge (Mass), 1994.

[18] Brezillon P. "Elaboration of the Contextual Graph Representation: from a contextual framework to an operational software", ISTE OpenScience, pp. 1-26, 2017.

[19] Cappelen H., Lepore E., "The Myth of Unarticulated Constituents", in O'Rourke and Washington (eds) Situating semantics: Essays in Honor of John Perry, MIT Press, 2007.

[20] Carnap R., Introduction to Semantics, Harvard: Harvard University Press, 1942.

[21] Carston R., Thoughts and Utterances, Oxford: Blackwell, 2002.

[22] Carston R., "Linguistic communication and the semantics/pragmatics distinction", Synthese, 165, pp. 321-345, 2008.

[23] Carston R., "Word Meaning, What is Said and Explicature" in F Domaneschi, C. Penco (eds), What is Said and What is Not, Stanford: CSLI, 2013.

[24] Corazza, E. "Some notes on point of view" in A. Capone et al. (eds.), Perspectives on Linguistic Pragmatics, Springer, 2013

[25] Cozzo C., "Does Epistemological Holism Lead to Meaning Holism?”, Topoi, 21, pp. 25-45, 2002.

[26] Davidson D., "Truth and Meaning" reprinted in D. Davidson 1984, Inquiries into Truth and Interpretation, Clarendon Press, Oxford, 1967.

[27] Davidson D., “A Nice Derangement of Epitaphs", in E. Lepore (ed.) Truth and interpretation. Perspectives in the Philosophy of D. Davidson, Blackwell, Oxford, pp. 433- 446, 1986.

[28] Delogu F., Drenhaus H., Crocker, M.W., "On the predictability of event boundaries in discourse: An ERP investigation", Memory \& cognition, pp. 1-11, 2017.

[29] Devitt M., "Three methodological Flaws in Linguistic Pragmatism” in F. Domaneschi, C. Penco, 2013.

[30] Domaneschi F., Carrea E., Penco C., Greco A., "Selecting presuppositions in conditional clauses" in Frontiers in Psychology, 10, 2016.

[31] Domaneschi F., Carrea E., Penco C., Greco A., "An experimental Approach to Attitudes towards Propositions”, in Pragmatics and Cognition, 2014.

[32] Domaneschi F., Carrea E., Penco C., Greco A., "The cognitive Load of presupposition triggers: Mandatory and optional repairs in presupposition failure", Language, Cognition and Neuroscience Vol. 29(1), 2014.

[33] Domaneschi F., Penco C. (eds.): What is Said and What is Not (on semantics/pragmatics interface), Stanford, CSLI, 2013. 
[34] Domaneschi F. Penco C., "Semiotics' internal conflict", in Rivista di Filosofia del Linguaggio, Vol. 9(1), pp. 215$231,2015$.

[35] Donnellan K., 'Reference and Definite Descriptions', The Philosophical Review 75: 261-230, 1968.

[36] Dummett M., Frege, Philosophy of Language, Duckworth, London, 1973.

[37] Dummett M., "Reply to Tennant" in B.M. Taylor (ed.) Michael Dummett. Contributions to Philosophy, Springer, 1987.

[38] Dummett M., The Logical Basis of Metaphysics, Duckworth, London, 1992.

[39] Dummett M., The Seas of Language, Clarendon, Oxford, 1993.

[40] Elbourne, P., Definite Descriptions. Oxford University Press, 2013.

[41] Fauconnier, G., Mappings in Thought and Language, Cambridge University Press, 1997.

[42] Fillmore, "Frame semantics and the nature of language", Annals of the New York Academy of Sciences, Vol. 280(1), pp. 20-32, 1976.

[43] Fillmore C.J., Baker C. 2010, "A Frame Approach to semantic Analysis", in The Oxford handbook of linguistic analysis, Oxford: Oxford University Press, pp. 313-339, 2010.

[44] Fodor J., Lepore E., Holism, Oxford: Blackwell, 1992.

[45] FrameNet Available at https://framenet.icsi.berkeley.edu/fndrupal/, International Computer Science Institute, Copyright 2000-2011.

[46] Frege G., Die Grundlagen der Aritmetik, W. Koebner, Breslau, 1884 (Trans., in Beaney, The Frege Reader), 1997.

[47] Frege G., "Über Sinn und Bedeutung", in Zeitschrift für Philosophie und philosophische Kritik, 100, pp. 25-50, 1892 (Engl. Tr, in Beaney, The Frege Reader, 1997).

[48] Frege G., "Der Gedanke. Eine logische Untersuchung". Beiträge zur Philosophie des Deutschen Idealismus, I, pp. 58-77, 1918 (Engl. Tr, in Beaney, The Frege Reader, 1997).

[49] Gauker C., Thinking Out Loud: An Essay on the Relation between Thought and Language, 1994.

[50] Gauker C., “What is a context of utterance?”, Philosophical Studies 91, 1998.

[51] Gauker C., "Indirect Discourse, Relativism and Contexts that points to other contexts", in F. Récanati, I. Stojanovic, N. Villanueva (Eds.) Context-dependence, perspective and relativity (Vol. 6), Walter de Gruyter, 2010.

[52] Giunchiglia F., "Contextual reasoning", in C. Dalla Pozza \& C. Penco(eds.) Linguaggi e Macchine - Special Issue of Epistemologia, 1993.

[53] Giunchiglia F., Ghidini C., "Local Models Semantics, or contextual reasoning= locality+ compatibility", Artificial Intelligence 127, pp. 221-259, 2002.

[54] Grice H.P., "Meaning" in The Philosophical Review, 66, pp. 377-388, 1957.

[55] Grice H.P., Studies in the Way of Words, Harvard UP, Cambridge (ma), 1989.

[56] Guha R.V., McCarthy J., "Varieties of contexts", Lecture Notes in Artificial Intelligence, pp. 164-177, 2003.

[57] Abu-Hakima S., Brézillon P, "Using Knowledge in its context: Report on the IJCAI-93 Workshop", AI Magazine, Spring, 16(1), pp.87-91, 1995.

[58] Heim I., The Semantics of Definite and Indefinite Noun Phrases, New York: Garland Press, 1988.

[59] Jaszczolt, K., "Default Semantics" in B. Heine \& H. Narrog, (eds) The Oxford Handbook of Linguistic Analysis,

Oxford: Oxford University Press, pp. 193-221, 2010.

[60] Kaplan, D., "Demonstratives", In: Almog, J. Perry, J. and Wettstein, H. (eds), Themes from Kaplan, Oxford: Oxford University Press, pp. 481-563, 1989.

[61] Kaplan D., "An Idea of Donnellan" in J. Almog and P. Leonardi, Having in Mind, The Philosophy of Keith Donnellan, Oxford: Oxford University Press, pp. 176-184, 2012.

[62] Korta, K., Perry J., The Pragmatic Circle. In Synthese, 165, pp. 347-57, 2008.

[63] Korta K., Perry J., Critical Pragmatics: An inquiry into Reference and Communication, Cambridge: Cambridge University Press, 2011. 
[64] Kripke, S. 1975, "Speaker's Reference and Semantic Reference”, in French P. A., Uehling T. E., Wettstein H. K. (eds.), Contemporary Perspectives in the Philosophy of Language, Univ. of Minnesota Press, 1975.

[65] Kripke S., "Frege's Theory of Sense and Reference: Some Exegetical Notes”, Theoria , 74, pp. 181-218, 2008.

[66] Kripke S., "Presupposition and Anaphora: Remarks on the formulation of the Projection Problem" in Philosophical Troubles, Oxford: Oxford University Press, pp. 351-372, 2011.

[67] Lebois, L.A., Wilson-Mendenhall, C.D., Barsalou, L.W., "Putting everything in context", Cognitive science, Vol. 39(8), pp. 1987-1995, 2015.

[68] Lewis, D., "Index, Context and Content". In S. Kranger, S. Ohman (eds), Philosophy and Grammar, Reidel, pp. 79$100,1980$.

[69] Ludlow, P., Neale S., "Descriptions", in M. Devitt, R. Hanley (eds), The Blackwell Guide to the Philosophy of Language, Blackwell, 2006.

[70] Marconi D., Lexical Competence, MIT Press, Cambridge (Mass.), 1997.

[71] McCarthy J., "Generality in A.I.", reprinted in McCarthy, Formalizing Commonsense (edited by V. Lifschitz), Ablex, 1990.

[72] McCarthy J., "Notes on Formalizing Contexts" in Proc.13 IJCAI, Chambery, pp.555-560, 1993.

[73] McCarthy J., “A logical AI aproach to context”, Stanford University, 1996.

[74] McCarthy J., Buvac S., "Formalizing contexts. Expanded notes" in A. Aliseda. van R. Glabbeek, D. Westerstähl (eds), Computing Natural language, Stanford: CSLI, 1997.

[75] Minsky M., "A framework for representing knowledge”, in P.H. Winston (ed.), The Psychology of Computer Vision, McGraw-Hill, New York, pp. 211-277, 1975.

[76] Minsky M., "The society of mind”, In: New York: Simon \& Schuser Peter, Context Sensitivity and Semantic Minimalism, Oxford, Oxford University Press, pp. 240-50, 1988.

[77] McFarlane J., Nonindexical Contextualismm Synthese 166, pp. 231-50, 2009.

[78] Neale S., "On being Explicit” in Mind and Language, 15, pp. 284-294, 2000.

[79] Neale S., Descriptions. Cambridge, MA: MIT Press/Bradford Books, 1990.

[80] Neale S., "This, that, and the other", in Descriptions and Beyond (eds. M. Reimer and A. Bezuidenhout), Oxford: Oxford University Press, pp. 68-182, 2004.

[81] Neale S., “A century later”, in Mind, vol. 114, 456, pp. 809-71, 2005.

[82] Neale S., "On Location” Situating Semantics: Essays on the Philosophy of John Perry, ed. by Michael O’Rourke and Corey Washington. Cambridge, MA: MIT Press, pp. 251-393, 2007.

[83] Neale S., "Implicit and aphonic reference." In G. Ostertag (ed.) Meanings and Other Things: Essays in Honor of Stephen Schiffer, Oxford: Oxford Unviersity Press, 2016.

[84] Pagin P., "Compositionality and context", In G. Preyer and G. Peter (eds.) Contextualism in philosophy, Oxford, Oxford Unviersity Press, pp. 303-48, 2005.

[85] Penco C., "Objective and Cognitive Context", in P. Bouquet, P. Brézillon, L. Serafini, F. Castellani (eds.) 2nd Conference on Modeling and Using Context (CONTEXT-99), Springer, pp. 270-283, 1999.

[86] Penco C., "Frege, sense and limited rationality", Modern Logic Vol.9/29, pp. 53-65, 2001.

[87] Penco C., "Local Holism", in V. Akman, P. Bouquet, R. Thomason, R.A. Young (eds.) Third Conference on Modeling and Using Context [LNAI 2116] Springer, pp. 290-303, 2001.

[88] Penco C. (ed.), The Contextual Turn (Italian: la Svolta contestuale), Milano: McGrow Hill, 2002.

[89] Penco C., "Holism, Strawberries and Hairdryers" in Topoi, pp. 47-54, 2002.

[90] Penco C., "Frege: Two thesis, two senses", in History and Philosophy of Logic. 24/2, pp. 87-109, 2003.

[91] Penco C., "Wittgenstein, Locality and Rules" in E.Picardi, A.Coliva, Wittgenstein Today, Padova: Il Poligrafo pp. 249-274, 2004.

[92] 2007 "Idiolect and Context", in R.E.Auxier and L.E. Hahn (eds.) The Philosophy of Michael Dummett - Library of Living Philosophers, vol. XXXI, pp. 567-590, 2007. 
[93] Penco C., "Rational procedures: A Neo-Fregean Perspective on Thought and Judgement" in Yearbook of Philosophical Hermeneutics: The dialogue, Münster, pp. 137-153, 2009.

[94] Penco C., "Essentially Incomplete Descriptions" in European Journal of Analytic Philosophy, 6, pp. 47.66, 2010.

[95] Penco C., "Indexicals as demonstratives: on the debate between Kripke and Künne" in Grazer Philosophische Studien, 88, 2013.

[96] Penco C., "Frege's Theory of Demonstratives as a Model for Indexical Thought" in Dieter Shott (Hrsg.) Frege: Freund(e) un Feind(e), Berlin: Logos, pp. 201-216, 2015.

[97] Penco C., "Context Dependence, MOPs, WHIMs and Procedures: Recanati and Kaplan on Cognitive Aspects in semantics", in Lecture Notes in Artificial Intelligence 9405, pp. 410-422, 2015.

[98] Penco C., "Loose Talk", in Maria Ponte \& Kepa Korta editors, Reference and Representation in Language and Thought, Oxford: Oxford U.P., 2017.

[99] Penco C., Vignolo M., "Converging towards What? On semantic and pragmatic competence" in P. Bouquet, L. Serafini, Context representation and reasoning, CEUR-WS, vol.136, 2005.

[100] Penco C., Vignolo M., "Varieties on Contexts" in Workshop on Context in Philosophy -inside the $10^{\text {th }}$ Congress on Modelling and Using Contexts, CEUR Proceedings 1945, pp. 1-5, 2017.

[101] Perry J., "Indexicals and Demonstratives", in Robert Hale and Crispin Wright, eds, Companion to the Philosophy of Language, Oxford: Blackwells Publishers, 1997.

[102] Perry J., "Contexts and Unarticulated Constituents". Proceedings of the CSLI Amsterdam Logic, Language and Computation Conference. Stanford: CSLI Publications, 1995.

[103] Perry J., "Using Indexicals" In M. Devitt, R. Hanley (eds), The Blackwell Guide to the Philosophy of Language, Oxford, Blackwell, pp. 314-34,2006.

[104] Predelli S., “The Teetotaler and His Martini”. Mind and Language, Vol. 15(5), pp. 511, 2000.

[105] Quine W.V.O., Word and Object, MIT Press, Cambridge (Mass), 1960.

[106] Recanati F., "Literalism and Contextualism". In Gerhard Preyer \& Georg Peter (eds.), Contextualism in Philosophy: Knowledge, Meaning, and Truth. Oxford University Press. pp. 171-196, 2005.

[107] Recanati F., Truth Conditional Pragmatics, Oxford: Clarendon Press, 2010.

[108] Reimer, M., Bezuidenhout A. (eds), Descriptions and beyond. Oxford, Clarendon Press, 2004.

[109] Russell G., Truth in virtue of meaning. A defense of the analytic/synthetic distinction, Oxford: Oxford University Press, 2008.

[110] Sainsbury M., “Two ways to smoke a sigarette”. Ratio, 14, pp. 386-406, 2001.

[111] Schank, R. C., Abelson, R. P., Scripts, plans, goals and understanding: An inquire into human knowledge structures. Hillsdale: L. Erlbaum, 1977.

[112] Schiffer S., Descriptions, Indexicals and Belief Reports. In Mind, Vol. 104, pp. 107-31, 1995.

[113] Sperber D., Wilson D., Relevance: Communication and Cognition. Oxford, 1986.

[114] Stalnaker R., "On the representation of context" Journal of Logic Language and Information Vol. 7, pp. 3-19, 1998.

[115] Stalnaker R., “Common Ground”, Linguistics and Philosophy Vol. 25, pp. 701-721, 2002.

[116] Stalnaker R., Context, Oxford: Oxford University Press, 2014.

[117] Stanley J., "Semantics in context", In Preyer G. (ed.) Contextualism in Philosophy. Oxford, Oxford University Press, 2005.

[118] Stanley J. and Szabò Z., On quantifier domain restriction, Mind \& Language, Vol. 15, pp. 219-61, 2000.

[119] Stanley J., Williamson T., Quantifiers and context-dependence. Analysis, Vol. 55, pp. 291-95, 1995.

[120] Szabó Z., "Descriptions and Uniqueness” Philosophical Studies, Vol. 101, pp. 29-57, 2000.

[121] Szabó Z. (ed.), Semantics versus Pragmatics. Clarendon Press, Oxford, 2005.

[122] Tennant N., "Holism, molecularity and truth". In B.M.Taylor (ed.) Michael Dummett. Contributions to Philosophy, Springer, pp. 31-58, 1987. 
[123] Travis C., "Pragmatics". In: Travis, Occasion Sensitivity: Selected Essays, 2008.

[124] Unsteinsson E., “Compositionality and sandbag semantics”, Synthese, Vol. 191(14), pp. 3329-3350, 2014.

[125] Vignolo M., Use against Skepticism, Cambridge Scholar Publishing, Newcastle, 2009.

[126] Westerstähl D., "Determiners and context sets". In J. van Benthem and A. ter Meulen (eds.), Generalized Quantifiers in Natural Language, Foris, Dordrecht, pp. 45-71, 1985.

[127] Wettstein H., Demonstrative reference and definite descriptions. Philosophical Studies, Vol. 40, pp. 241-57, 1981.

[128] Williamson T., "Knowledge, Context, and the Agent's point of view", in G. Preyer and G. Peter (eds.) Contextualism in philosophy, Oxford, Oxford University press, pp. 91-114, 2005.

[129] Winograd T, Understanding Natural Language, New York: Academic Press, 1972

[130] Wittgenstein L. Tractatus Logico-Philosophicus, London, Routledge \& Kegan Paul, 1921.

[131] Wittgenstein L., Philosophical Investigations, Blackwell, Oxford, 1953.

[132] Yeh W., Barsalou L.W., "The situated nature of concepts”, American Journal of Psychology 119, pp. 349-384, 2006 . 